\title{
Intraislet glucagon signaling is critical for maintaining glucose homeostasis
}

\author{
Lu Zhu, ${ }^{1}$ Diptadip Dattaroy, ${ }^{1}$ Jonathan Pham, ${ }^{1}$ Lingdi Wang, ${ }^{2}$ Luiz F. Barella, ${ }^{1}$ Yinghong Cui, \\ Kenneth J. Wilkins, ${ }^{3}$ Bryan L. Roth, ${ }^{4}$ Ute Hochgeschwender, ${ }^{5}$ Franz M. Matschinsky, ${ }^{6}$ \\ Klaus H. Kaestner, ${ }^{6}$ Nicolai M. Doliba, ${ }^{6}$ and Jürgen Wess ${ }^{1}$
}

${ }^{1}$ Molecular Signaling Section, Laboratory of Bioorganic Chemistry, National Institute of Diabetes and Digestive and Kidney Diseases, Bethesda, Maryland, USA. 'Laboratory of Mitochondrial Biology and Metabolism, National Heart, Lung and Blood Institute, Bethesda, Maryland, USA. ${ }^{3}$ Biostatistics Program, National Institute of Diabetes and Digestive and Kidney Diseases, NIH, Bethesda, Maryland, USA. ${ }^{4}$ Department of Pharmacology, University of North Carolina at Chapel Hill School of Medicine, Chapel Hill, North Carolina, USA. ${ }^{5}$ Neuroscience Program and College of Medicine, Central Michigan University, Mt. Pleasant, Michigan, USA. ${ }^{6}$ Institute of Diabetes, Obesity, and Metabolism, Perelman School of Medicine, University of Pennsylvania, Philadelphia, Pennsylvania, USA.

Clucagon, a hormone released from pancreatic $\alpha$ cells, plays a key role in maintaining proper glucose homeostasis and has been implicated in the pathophysiology of diabetes. In vitro studies suggest that intraislet glucagon can modulate the function of pancreatic $\beta$ cells. However, because of the lack of suitable experimental tools, the in vivo physiological role of this intraislet cross-talk has remained elusive. To address this issue, we generated a mouse model that selectively expressed an inhibitory designer GPCR (Gi DREADD) in $\alpha$ cells only. Drug-induced activation of this inhibitory designer receptor almost completely shut off glucagon secretion in vivo, resulting in markedly impaired insulin secretion, hyperglycemia, and glucose intolerance. Additional studies with mouse and human islets indicated that intraislet glucagon stimulates insulin release primarily by activating $\beta$ cell CLP-1 receptors. These findings strongly suggest that intraislet glucagon signaling is essential for maintaining proper glucose homeostasis in vivo. Our work may pave the way toward the development of novel classes of antidiabetic drugs that act by modulating intraislet cross-talk between $\alpha$ and $\beta$ cells.

Conflict of interest: The authors have declared that no conflict of interest exists.

Copyright: (c) 2019 American Society for Clinical Investigation

Submitted: February 6, 2019

Accepted: April 17, 2019

Published: May 16, 2019

Reference information: /Cl Insight. 2019;4(10):e127994. https://doi. org/10.1172/jii.insight.127994

\section{Introduction}

Glucagon is a polypeptide hormone that plays a key role in the regulation of glucose homeostasis (1-3). It is secreted from $\alpha$ cells of the pancreatic islets of Langerhans to increase blood glucose levels in times of fasting and to counteract the actions of insulin in the liver and other tissues (1-3). Accumulating evidence suggests that $\alpha$ cell dysfunction contributes to impaired glucose homeostasis in type 1 and 2 diabetes $(1,2,4)$. At present, the role of glucagon secretion from $\alpha$ cells in the pathophysiology of diabetes is not well understood. Thus, a better understanding of $\alpha$ cell physiology and pathophysiology is likely to provide novel insights into impaired glucose homeostasis characteristic for type 1 and 2 diabetes and to identify novel targets for the development of antidiabetic drugs.

In vitro studies suggest that $\alpha$ cell glucagon can modulate $\beta$ cell function $(2,5)$. However, it remains unknown whether this intraislet cross-talk plays a role in regulating glucose homeostasis in vivo, primarily due to the lack of suitable animal models. To address this issue, we established what we believe to be a novel mouse line that enabled us to acutely suppress glucagon secretion from pancreatic $\alpha$ cells in a drug-dependent fashion in vivo. This mouse line, referred to as $\alpha$-GiD herein, expressed an inhibitory designer GPCR in $\alpha$ cells only. This designer GPCR represents a DREADD (designer receptor exclusively activated by a designer drug) that is selectively coupled to inhibitory $G$ proteins of the $G_{i}$ family (6-8). Importantly, this DREADD, referred to as GiD herein, can be activated by a small-molecule compound called clozapine N-oxide (CNO), an agent that is otherwise pharmacologically inert (6-8). This mouse model provided us with the opportunity to acutely inhibit the activity of $\alpha$ cells and dramatically lower plasma glucagon levels in vivo.

Here we show that intraislet glucagon signaling is required for the efficient release of insulin in vivo and for the proper regulation of blood glucose homeostasis. Strategies aimed at enhancing intraislet glucagon signaling could prove useful to promote insulin secretion for therapeutic purposes. 


\section{Results}

Generation of mice expressing the GiD designer receptor selectively in pancreatic $\alpha$ cells. To generate the $\alpha$-GiD mutant mice, we used a recently developed mouse strain in which the expression of GiD (also known as $\mathrm{hM} 4 \mathrm{Di})(6,9)$ is dependent on the activity of Cre recombinase (Rosa26-LSL-hM4Di mice) (10). We crossed Rosa26-LSL-hM4Di mice with a recently developed, improved Gcg-CreER ${ }^{T 2}$ mouse line that expresses $\mathrm{CreER}^{\mathrm{T} 2}$ following tamoxifen (TMX) treatment from the endogenous preproglucagon locus without disrupting preproglucagon expression (11). This latter mouse line exhibits high recombination efficiency in pancreatic $\alpha$ cells and enteroendocrine $L$ cells (11). The resulting mutant mice carrying both the Rosa26-LSL-hM4Di and Gcg-CreER ${ }^{T 2}$ alleles were injected i.p. with TMX for 6 consecutive days (2 mg per day). TMX-injected Rosa26-LSL-hM4Di mice lacking the Gcg-CreER $R^{T 2}$ transgene served as control animals throughout the study. All mouse strains were maintained on a C57BL/6 background.

Because of the different kinetics of cell turnover between intestinal L cells and pancreatic $\alpha$ cells, we were able to obtain mutant mice that expressed GiD selectively in $\alpha$ cells. This was achieved by simply waiting approximately 4 weeks following the last TMX injection, allowing the Cre-modified L cells to be replaced by WT L cells originating from the crypts (11).

To confirm that the GiD receptor was selectively expressed in islets of TMX-treated Rosa26- $L S L-h M$ $4 D i$ Gcg-CreER ${ }^{T 2}$ mice, we carried out immunoblotting studies with cell lysates prepared from pancreatic islets and several other tissues, including ileum and colon, where most GLP-1-expressing L cells are localized. GiD protein was detected by an anti-HA antibody that recognized the HA-epitope tag fused to the extracellular N-terminus of GiD (10). Supplemental Figure 1 (supplemental material available online with this article; https://doi.org/10.1172/jci.insight.127994DS1) shows that the GiD construct was selectively expressed in pancreatic islets of TMX-treated Rosa26-LSL-hM4Di Gcg-CreER ${ }^{T 2}$ mice but not in control mice.

To demonstrate that the GiD receptor was selectively expressed by pancreatic $\alpha$ cells, we carried out immunofluorescence staining experiments using slices prepared from pancreatic islets of TMX-treated Rosa26-LSL-hM4Di Gcg-CreER ${ }^{T 2}$ and control mice. We found that approximately $96 \%$ of glucagon-expressing islet cells ( $\alpha$ cells) coexpressed HA-tagged GiD protein (Figure 1A, top). In contrast, GiD expression was not detectable in islet cells that expressed insulin (Figure 1B, top) or other islet cells not expressing glucagon. No GiD expression was observed with slices from pancreatic islets prepared from control mice (Figure 1, bottom left). For this analysis, nearly 1000 islet cells from 3 Rosa26-LSL-hM4Di Gcg-CreER ${ }^{T 2}$ mice and 3 control mice were studied.

These observations clearly indicate that the TMX-treated Rosa26-LSL-hM4Di Gcg-CreER ${ }^{T 2}$ mice selectively express the GiD DREADD in pancreatic $\alpha$ cells. For the sake of brevity, we refer to these mutant mice as $\alpha$-GiD mice throughout.

In vivo metabolic studies with control and $\alpha$-GiD mice. We subjected the $\alpha$-GiD mice, along with their control littermates, to a series of in vivo metabolic tests. Unless indicated otherwise, adult male mice that were at least 12 weeks old were used for all experiments. The 2 mouse strains did not show any significant differences in body weight (Supplemental Figure 2A). $\alpha-\mathrm{GiD}$ and control mice that had free access to food or that had been fasted overnight for 12 hours showed comparable plasma glucagon, plasma insulin, and blood glucose levels (Supplemental Figure 2, B-D).

To activate the GiD receptor in $\alpha$ cells of $\alpha$-GiD mice, we injected $\alpha$-GiD mice with a single dose of CNO (1 mg/kg i.p.). Strikingly, CNO treatment of either fasted or freely fed $\alpha$-GiD mice caused dramatic reductions (by $\sim 90 \%$ ) in plasma glucagon levels over the entire 30-minute observation period (Figure 2, A and D). This effect was accompanied by pronounced reductions in plasma insulin levels (Figure 2, B and E). In control mice that did not express the GiD receptor, the CNO injection had no significant effect on plasma insulin levels (Figure 2, B and E) but caused a modest decrease in plasma glucagon levels (Figure 2, A and D). To rule out the possibility that this latter response was caused by an off-target effect of CNO, we carried out analogous studies with WT C57BL/6 mice. We found that CNO $(1 \mathrm{mg} / \mathrm{kg}$ i.p.) or saline treatment of fasted WT mice caused reductions in plasma glucagon levels that were similar in magnitude to those observed with CNO-treated $\alpha-$ GiD control mice (Supplemental Figure $3 \mathrm{~A}$ ). This observation strongly suggests that the i.p. injection procedure itself can lower plasma glucagon levels, at least under the experimental conditions used in this study. CNO or saline treatment of WT mice had no significant effect on plasma insulin levels (Supplemental Figure 3B).

The CNO-induced reductions in plasma glucagon and insulin levels displayed by the $\alpha$-GiD mice had little effect on blood glucose levels during the first 30 minutes after CNO injection, as compared 
with CNO-injected control mice (Figure 2, C and F). Following CNO (1 mg/kg i.p.) treatment of $\alpha$-GiD mice, plasma glucagon and insulin levels remained greatly reduced for at least 2 hours (Supplemental Figure 4, A and B). Interestingly, $\alpha$-GiD mice, but not their control littermates, displayed significantly increased blood glucose levels 60-120 minutes after CNO injection (Supplemental Figure $4 \mathrm{C})$, most likely due to the long-lasting decrease in plasma insulin levels. CNO treatment of $\alpha-\mathrm{GiD}$ mice and their control littermates had little or no effect on plasma GLP-1, GIP, and somatostatin (SST) levels (Supplemental Figure 5).

All experiments described above were carried out with male mice. Supplemental Figure 6 shows that CNO treatment ( $1 \mathrm{mg} / \mathrm{kg}$ i.p.) of female $\alpha$-GiD mice caused a dramatic reduction in plasma glucagon and a significant decrease in plasma insulin levels, as observed with male $\alpha$-GiD mice. Moreover, blood glucose levels were significantly elevated 2 hours after CNO treatment of female $\alpha$-GiD mice, as compared with their control littermates (Supplemental Figure 6C).

We next subjected $\alpha$-GiD mice and control littermates to glucose and insulin tolerance tests (Figure 3 ). Injection of mice with glucose alone ( $2 \mathrm{~g} / \mathrm{kg}$ i.p.) caused similar increases in blood glucose levels in $\alpha$-GiD mice and control littermates (Figure 3A). In contrast, coinjection of glucose ( $2 \mathrm{~g} / \mathrm{kg}$ i.p.) with CNO ( $1 \mathrm{mg} /$ $\mathrm{kg}$ i.p.) caused significantly greater blood glucose excursions in $\alpha$-GiD mice, as compared with control littermates (Figure 3B), indicating that activation of $\alpha$ cell $\mathrm{GiD}$ receptors causes impaired glucose tolerance. This decrease in glucose tolerance was associated with a dramatic reduction in plasma glucagon levels and a greatly reduced insulin response, as compared with coinjected control animals (Figure 3, C and D). One possible explanation for this finding is that the release of intraislet glucagon is required for the ability of glucose to stimulate insulin release from $\beta$ cells with high efficacy.

Acute injection of mice with insulin alone $(0.75 \mathrm{U} / \mathrm{kg}$ i.p; insulin tolerance test) caused comparable decreases in blood glucose levels in $\alpha$-GiD mice and control littermates (Figure $3 \mathrm{E}$ ). Coinjection of insulin (0.75 U/kg i.p.) with CNO (1 mg/kg i.p.) caused a slight increase in insulin sensitivity only at one single time point (45 minutes after injection) (Figure $3 \mathrm{~F}$ ). At the same time, insulin/CNO coinjection almost completely shut down glucagon secretion in $\alpha$-GiD mice (Figure 3G). In contrast, the same treatment caused an increase in plasma glucagon levels in control mice (Figure 3G). Coinjection of insulin and CNO caused similar increases in plasma insulin levels in $\alpha$-GiD mice and control littermates (Figure $3 \mathrm{H}$ ).

Perifusion studies with pancreatic islets prepared from control and $\alpha$-GiD mice. On the basis of the outcome of in vivo metabolic studies, we hypothesized that the impairments in glucose tolerance and glucose-stimulated insulin secretion (GSIS) observed after CNO treatment of $\alpha-\mathrm{GiD}$ mice (Figure 3, B and D) were caused by the relative lack of intraislet glucagon. To further test this hypothesis, we carried out a series of perifusion studies using islets prepared from control and $\alpha$-GiD mice.

We initially monitored glucagon and insulin release in control islets at low and high glucose concentrations ( $3 \mathrm{mM}$ and $12 \mathrm{mM}$, respectively). We also quantitated glucagon and insulin release after addition of a physiological amino acid mixture (AAM) that promotes glucagon release from $\alpha$ cells (1-14). As expected, increasing the glucose concentration from 3 to $12 \mathrm{mM}$ led to a decrease in glucagon secretion but to an increase in insulin release (Figure 4, A and B). Addition of the AAM mixture at $12 \mathrm{mM}$ glucose led to a very robust increase in both glucagon and insulin secretion (Figure 4, A and B). The addition of CNO $(10 \mu \mathrm{M})$ to the perifusion fluid had no significant effect on glucagon or insulin release from control islets (Figure $4, \mathrm{~A}$ and $\mathrm{B}$ ).

A completely different pattern emerged when we studied glucagon and insulin secretion from islets prepared from $\alpha$-GiD mice ( $\alpha$-GiD islets) (Figure $4, \mathrm{C}$ and $\mathrm{D}$ ). In the presence of $\mathrm{CNO}(10 \mu \mathrm{M})$, glucagon release was significantly reduced, independent of the glucose concentration in the perifusion medium. Most notably, the very pronounced increase in glucagon secretion seen after addition of AAM in the absence of CNO was nearly abolished in $\alpha$-GiD islets in the presence of CNO (Figure 4C). The glucose/ AAM-induced decreases in glucagon secretion caused by CNO treatment were accompanied by marked reductions in insulin release (Figure 4D). Thus, these in vitro data strongly support our hypothesis that glucagon released from $\alpha$ cells acts in a paracrine fashion on $\beta$ cells and that this cross-talk is required for the ability of $\beta$ cells to stimulate insulin secretion with high efficacy.

To further support the conclusion that the insulin secretion deficit observed with CNO-treated $\alpha-G i D$ islets was indeed caused by reduced intraislet glucagon signaling, we carried out the "rescue experiment" shown in Figure 5. Specifically, we perifused $\alpha$-GiD islets with $12 \mathrm{mM}$ glucose and AAM, either in the absence or the presence of CNO $(10 \mu \mathrm{M})$, as described above. As expected, insulin release was significantly 
A
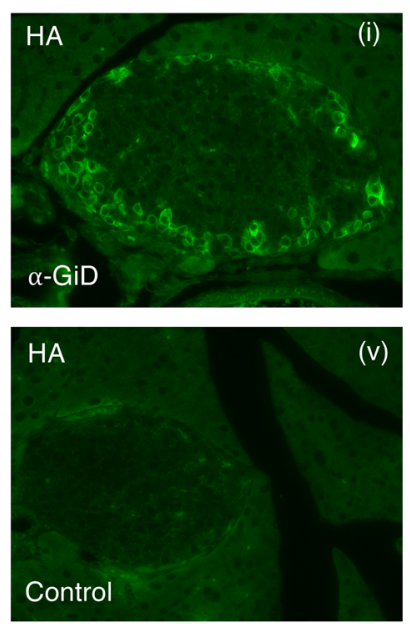

B
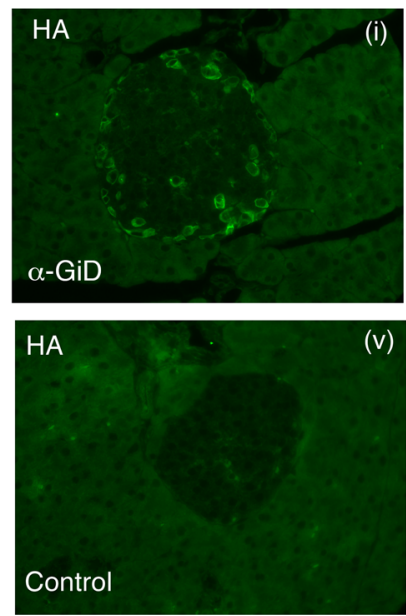

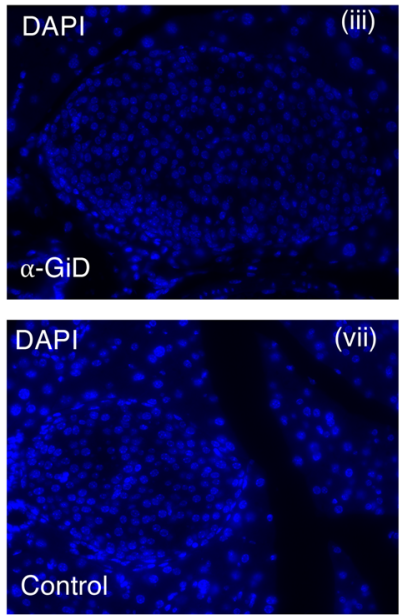

(ii)
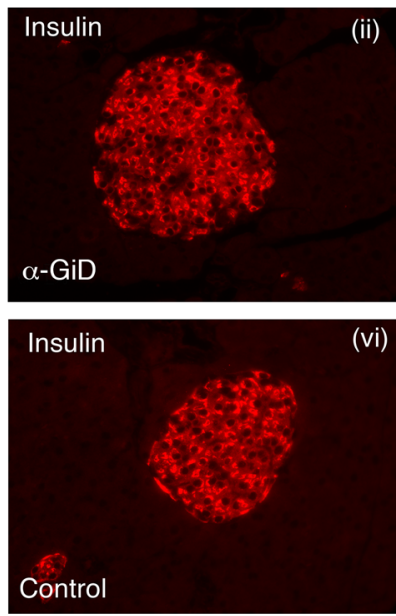
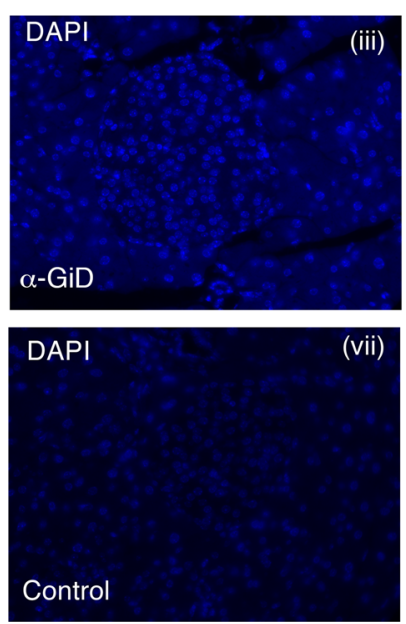


Figure 1. Selective expression of GiD in pancreatic $\alpha$ cells. Immunofluorescent staining of slices from pancreatic islets of $\alpha$-CiD and control mice. Note that the GiD receptor carried an $\mathrm{N}$-terminal HA-tag, allowing its localization with an anti-HA antibody. Nuclei were stained blue with DAPI mounting medium. (A) Slices from $\alpha$-GiD mice (i-iv) and control littermates (v-viii) were stained for HA-GiD (Alexa Fluor, green) and glucagon (Alexa Fluor, red). (B) Slices from $\alpha$-CiD mice (i-iv) and control littermates ( $\mathrm{v}$-viii) were stained for HA-GiD (Alexa Fluor, green) and insulin (Alexa Fluor, red). These representative images show that the $\mathrm{GiD}$ receptor is not expressed in control islets but is selectively expressed by $\alpha$ cells of islets from $\alpha$-CiD mice. Original magnification, $\times 40$.

reduced in the CNO-treated $\alpha$-GiD islets under these experimental conditions (Figure 5). We next added glucagon $(10 \mathrm{nM})$ to the islet preparations 15 minutes after costimulation of islets with $12 \mathrm{mM}$ glucose and AAM. Strikingly, the addition of glucagon to the CNO-treated $\alpha$-GiD islets fully restored normal insulin secretion, as compared with glucagon-treated $\alpha-\mathrm{GiD}$ islets that had not been exposed to CNO (Figure 5). This observation strongly supports the concept that the impairment in insulin secretion displayed by the CNO-treated $\alpha$-GiD islets was caused by the relative lack of intraislet glucagon.

Glucagon released from $\alpha$ cells acts primarily on $\beta$ cell GLP-1 receptors to greatly enhance insulin secretion. Pancreatic $\beta$ cells are known to express glucagon and GLP-1 receptors, 2 GPCRs known to enhance GSIS (15). In fact, GLP-1 receptor agonists such as exendin-4 are in therapeutic use to promote insulin secretion in patients suffering from type 2 diabetes $(16,17)$. Previous studies have shown that glucagon is able to activate both of these receptors, although with different potencies $(5,18)$. In contrast to glucagon, the levels of the active form of GLP-1 are extremely low or undetectable in mouse pancreatic islets $(5,19)$.

Based on these considerations, we next tested the hypothesis that glucagon released from $\alpha$ cells acts on $\beta$ cell glucagon and/or GLP-1 receptors to promote the secretion of insulin. Specifically, we subjected islets prepared from WT C57BL/ 6 mice to same experimental protocol as described above for $\alpha$-GiD islets (Figure 6). WT islets were perifused in the presence of exendin(9-39) (Ex-9; $1 \mu \mathrm{M})$, a selective GLP-1 receptor antagonist (20, 21); adomeglivant (Ado; also known as LY2409021; $1 \mu \mathrm{M}$ ), a selective glucagon receptor antagonist $(22,23)$; or a mixture of Ex-9 and Ado (1 $\mu \mathrm{M}$ each). 
A

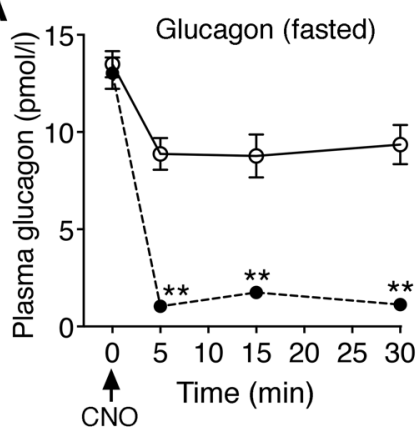

D

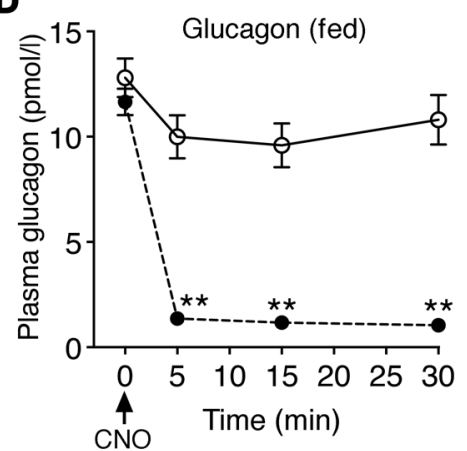

B

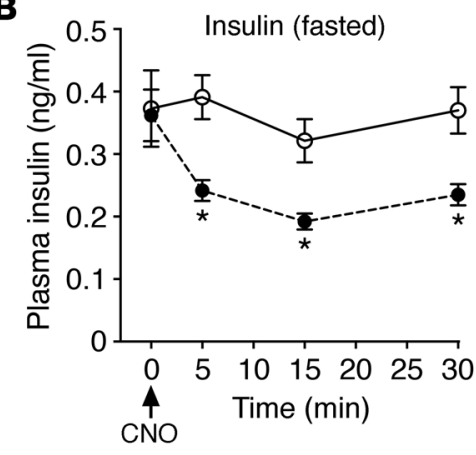

E

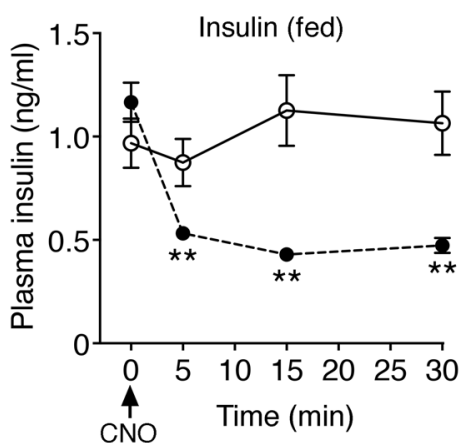

C

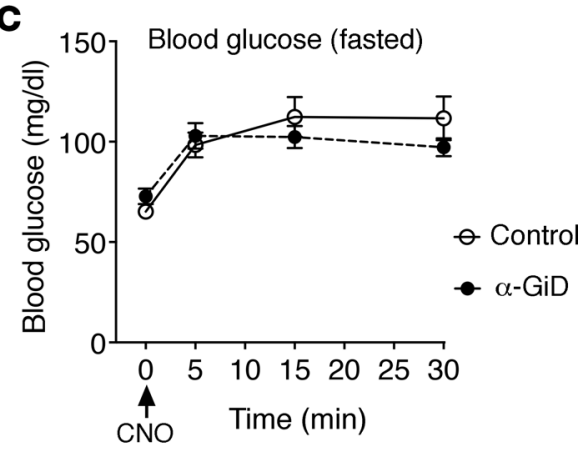

$\mathbf{F}$

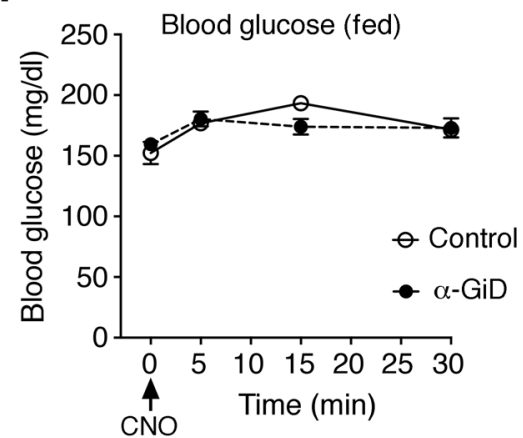

Figure 2. Acute activation of $\alpha$ cell GiD almost completely shuts down glucagon secretion in vivo. All mice ( $\alpha$-GiD mice and control littermates) were injected i.p. with CNO (1 mg/kg) at time "0." (A-C) Studies with fasted mice (overnight fast for 12 hours). (D-F) Studies with freely fed mice. Plasma glucagon ( $\mathbf{A}$ and $\mathbf{D}$ ), plasma insulin ( $\mathbf{B}$ and $\mathbf{E}$ ), and blood glucose (C and $\mathbf{F}$ ) levels were measured at the indicated time points using blood collected from the tail vein. All experiments were carried out with male littermates that were at least 12 weeks old. Data are given as mean \pm SEM $(\alpha$-CiD: $n=13 ;$ control: $n=6)$. ${ }^{*} P<0.05 ;{ }^{* *} P<0.01$ (mixed-effects repeated-measures ANOVA for after injection differences).

Perifusion experiments showed that the glucose/AAM-induced changes in glucagon secretion were not affected by the presence of Ex-9, Ado, or a combination of these 2 antagonists (Figure 6, A, C, and E, and Supplemental Figure 7, A, C, and E). In striking contrast, glucose- and glucose/AAM-induced insulin secretion responses were greatly reduced when WT islets were perifused in the presence of Ex-9 (Figure 6B and Supplemental Figure 7B). The presence of Ado in the perifusion fluid had no significant effect on glucose/AAM-induced increases in insulin release (Figure 6D and Supplemental Figure 7D). When perifusion studies were carried out in the simultaneous presence of Ex-9 and Ado, glucose/AAM-stimulated insulin secretion was also strongly reduced (Figure 6F and Supplemental Figure 7F). The Ex-9/Ado-induced inhibition of glucose/AAM-stimulated insulin release appeared slightly more robust than that observed after perifusion of WT islets with Ex-9 alone (Figure 6, B and F, and Supplemental Figure 7, B and F).

We also carried out perifusion experiments with human islets. These studies were done in the continued presence of physiological AAM to promote glucagon release and to more closely mimic physiological conditions (14). The addition of Ex-9 $(1 \mu \mathrm{M})$ had no significant effect on glucagon release throughout the perifusion period (Figure 6G). In contrast, GSIS was significantly reduced when Ex-9 was added prior to stimulation with $16.7 \mathrm{mM}$ glucose (Figure 6H). GSIS was reduced to a similar extent when human islets were exposed to a mixture of Ado and Ex-9 (1 $\mu \mathrm{M}$ each) (Supplemental Figure 8).

\section{Discussion}

In the present study, we generated a mouse model that allowed us to acutely and selectively inhibit glucagon release from pancreatic $\alpha$ cells in vivo. Specifically, we created mutant mice that selectively expressed an inhibitory designer GPCR (GiD) in $\alpha$ cells only ( $\alpha$-GiD mice).

It is known that glucagon (preproglucagon) is also expressed in the brain, particularly in the brainstem and hypothalamus (24). We were unable to detect the expression of the $\mathrm{GiD}$ designer receptor in the hypothalamus of $\alpha$-GiD mice (Supplemental Figure 1). It is therefore unlikely that brain expression of GiD affects the outcome of the reported in vivo data. 

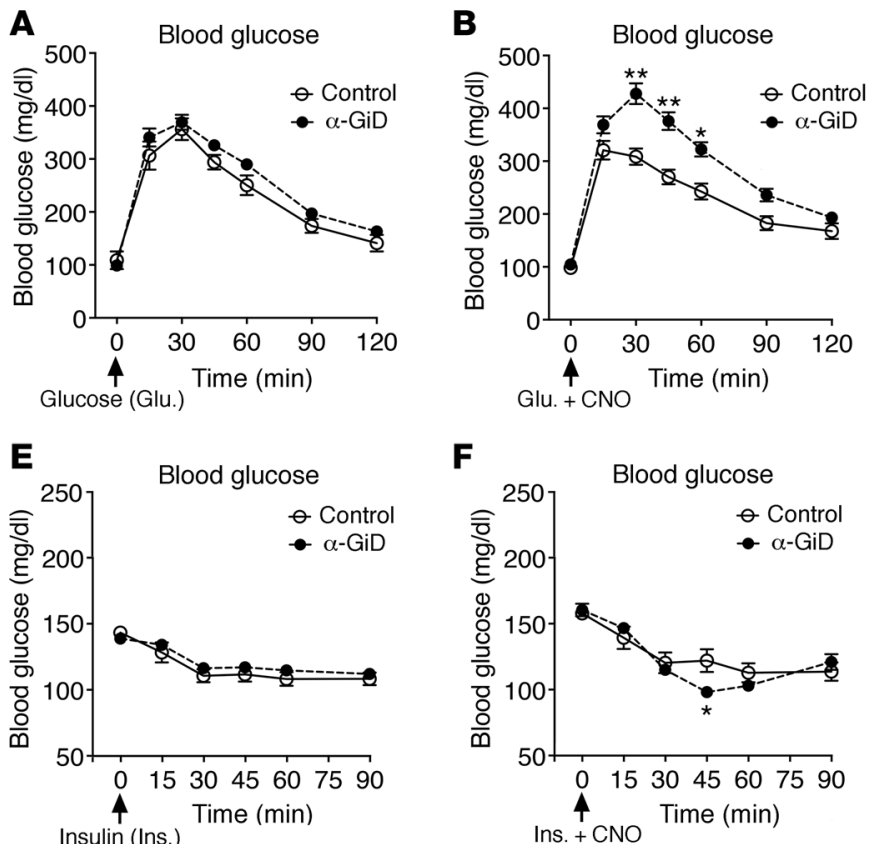
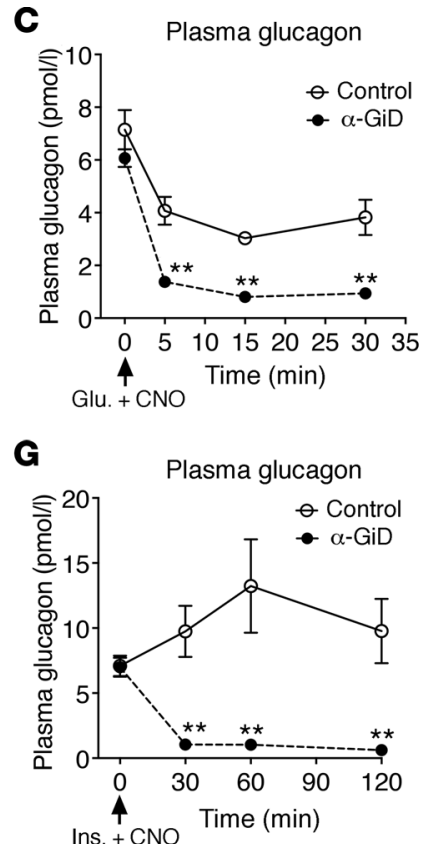



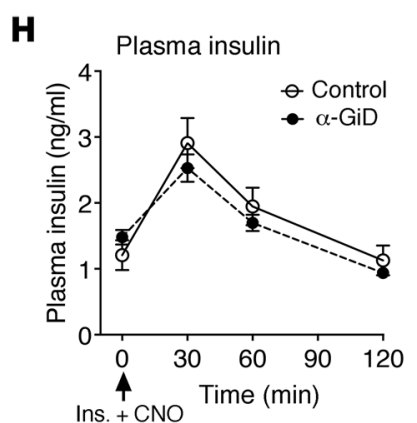

Figure 3. Acute activation of $\alpha$ cell GiD causes impaired glucose tolerance in $\alpha$-GiD mice. (A-D) Mice that had been fasted overnight were injected with glucose (2 g/kg i.p.), either in the absence or presence of CNO (1 mg/kg i.p). (A) i.p. glucose tolerance test (IGTT) in the absence of CNO. (B) IGTT in the presence CNO. (C) Plasma glucagon levels during IGTT in the presence of CNO. (D) Plasma insulin levels during IGTT in the presence of CNO. (E-H) Mice that had been fasted for 4 hours were injected with insulin ( $0.75 \mathrm{U} / \mathrm{kg}$ i.p.), either in the absence or presence of CNO (1 mg/kg i.p). (E) Insulin tolerance test (ITT) in the absence of CNO. (F) ITT in the presence CNO. (C) Plasma glucagon levels during ITT in the presence of CNO. (H) Plasma insulin levels during ITT in the presence of CNO. Blood samples were collected from the tail vein. All experiments were carried out with male littermates that were 20-30 weeks old. Data are given as mean \pm SEM ( $\alpha$-GiD: $n=13$; control: $n=6$ ). ${ }^{*} P<0.05$; ${ }^{*} P<0.01$ (mixed-effects repeated-measures ANOVA for after injection differences).

CNO treatment of $\alpha$-GiD mice led to a drastic reduction in plasma glucagon levels in $\alpha$-GiD mice (by $\sim 90 \%$ ) (Figure 2, A and D). Surprisingly, the resulting low circulating plasma glucagon levels did not result in hypoglycemia, even in CNO-treated $\alpha$-GiD mice that had been fasted overnight (Figure $2 \mathrm{C}$ ). The CNO-induced hypoglucagonemia was accompanied by a pronounced reduction in plasma insulin levels (Figure 2, B and E), most likely due to impaired intraislet glucagon signaling, as suggested by in vitro islet perifusion studies (see below). The ability of hypoinsulinemia to promote hepatic glucose production (25) provides a possible explanation for the observation that hypoglucagonemia did not cause hypoglycemia. It is also possible that euglycemia was maintained by compensatory, glucagon-independent mechanisms, including increased activity of hepatic adrenergic receptors (26) or enhanced hepatic corticosterone signaling (25). Consistent with this concept, adult $G c g$ mutant mice lacking functional glucagon had normal blood glucose levels, even after a 16-hour fast (27).

Based on the in vivo phenotypes displayed by the $\alpha$-GiD mice, we hypothesized that the impairments in glucose tolerance and GSIS observed with CNO-treated $\alpha$-GiD mice (Figure 3, B and D) might be due to decreased intraislet glucagon levels. To test this hypothesis, we performed a series of perifusion studies using islets prepared from control and $\alpha-\mathrm{GiD}$ mice. These studies, complemented by hormone release experiments carried out with human islets, indicated that efficient GSIS requires intraislet glucagon that acts primarily on $\beta$ cell GLP-1 receptors (Figures 4 and 6). On the other hand, $\beta$ cell glucagon receptors, which, like GLP-1 receptors, preferentially couple to $\mathrm{G}_{\mathrm{s}}(15)$, only make a minor contribution to this glucagon effect (Figures 4 and 6). One likely reason for this observation is that GLP-1 receptors are expressed at 10 - to 20 -fold higher levels than glucagon receptors in mouse islets (28). The results of the islet perifusion studies are summarized in a schematic fashion in Figure 7.

What is the likely mechanism through which activation of the GiD receptor suppresses $\alpha$ cell activity? Under physiological conditions, SST released from pancreatic $\delta$ cells strongly inhibits glucagon secretion from pancreatic $\alpha$ cells by activating SST-2 receptors (29). Activation of $\alpha$ cell SST-2 receptors leads to the opening of $\mathrm{G}$ protein-gated inwardly rectifying $\mathrm{K}^{+}$channels, thus suppressing electrical activity and directly inhibiting exocytosis (30). Like the GiD designer receptor, which is derived from the human $\mathrm{M}_{4}$ muscarinic receptor (6), the SST-2 receptor subtype is selectively linked to G proteins of the $G_{i}$ family (29). It is therefore likely that CNO-mediated activation of GiD inhibits $\alpha$ cell activity in a similar fashion. 

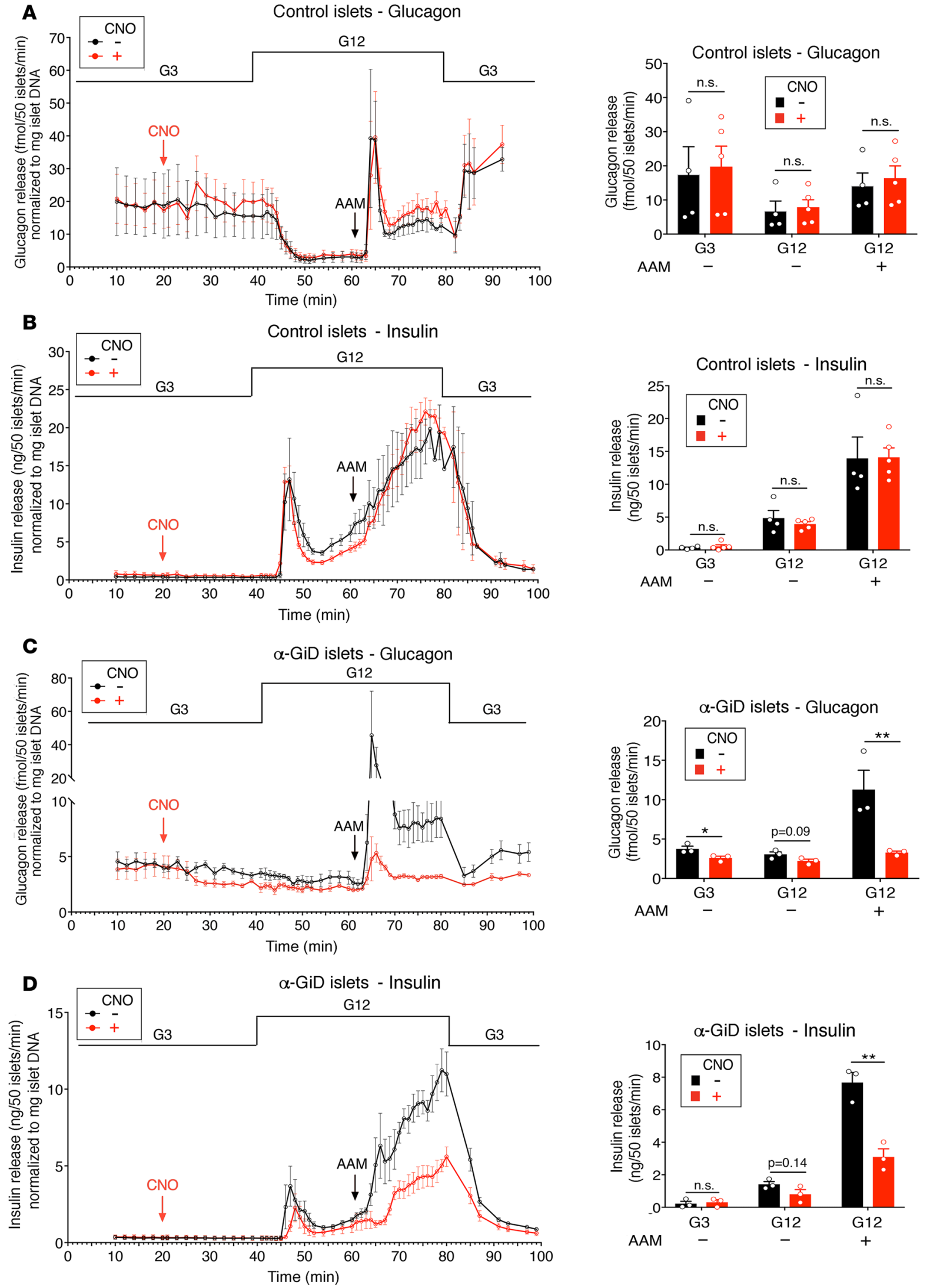
Figure 4. Activation of GiD in perifused $\alpha-G i D$ islets causes strong reductions in glucagon and insulin secretion. Islets from control and $\alpha$ - $G i D$ mice were perifused with the indicated glucose concentrations ( $3 \mathrm{mM}$ and $12 \mathrm{mM}$; $\mathrm{m} 3$ and G12, respectively) in the presence (red curve) or absence (black curve) of CNO $(10 \mu \mathrm{M})$. In the bar graphs, hormone secretion during specific time intervals was expressed as the average of all values measured during a particular perifusion period: $\mathrm{C} 3 \pm \mathrm{CNO}, 20-40$ minutes; $\mathrm{C} 12 \pm \mathrm{CNO}, 40-60$ minutes; $\mathrm{C} 12+\mathrm{AAM} \pm \mathrm{CNO}, 60-80$ minutes. (A) Glucagon secretion from control islets. (B) Insulin secretion from control islets. (C) Glucagon secretion from $\alpha$-GiD islets. (D) Insulin secretion from $\alpha$-GiD islets. The amounts of secreted glucagon and insulin were normalized to islet DNA content. All islets were prepared from male littermates that were 14-20 weeks old. Data are given as mean \pm SEM ( 3 or 4 perifusions with 50 islets per perifusion chamber; islets from 2 mice were pooled per perifusion experiment). ${ }^{*} P<0.05 ;{ }^{*} P<0.01$ (2-tailed Student's $t$ test). AAM, amino acid mixture (see Methods for details).

In a related study, Svendsen et al. (5) used isolated perfused mouse pancreata to study the potential role of intraislet glucagon signaling. This preparation offers the advantage that it maintains the local cytoarchitecture and microvasculature, ensuring normal flux of hormones, metabolites, and other agents between the different cell types. To acutely eliminate glucagon secretion from $\alpha$ cells, the authors used a mouse model that allows diphtheria toxin (DT) to selectively destroy proglucagon-producing $\alpha$ cells (DT-Gcg mice). In these DT-Gcg mice, glucagon output was drastically decreased, as compared with control mice. Strikingly, GSIS was also greatly reduced in pancreatic preparations from DT-Gcg mice (5). In agreement with this observation, we found that CNO-mediated suppression of glucagon secretion in $\alpha$-GiD pancreatic islets also caused a significant decrease in GSIS. By using pancreatic preparations from either whole-body or $\beta$ cell-specific glucagon and GLP-1 receptor-KO mice, Svendsen et al. concluded that the of loss of either glucagon or GLP-1 receptors alone has no effect on insulin secretion but that only combined blockade of both receptors causes reduced insulin release (5). In contrast, we clearly demonstrated that Ex-9, a highly selective GLP-1 receptor antagonist, strongly reduced insulin release in perifused pancreatic islets prepared from WT mice (Figure 6B). In contrast, Ado, a selective glucagon receptor blocker, did not affect insulin release in WT islets under the same experimental conditions (Figure 6D). It is likely that different experimental conditions (e.g., the use of perfused pancreata vs. perifused islets) and the use of different mouse models are responsible for the discrepant conclusions regarding the relative roles of $\beta$ cell GLP-1 and glucagon receptors in regulating insulin release stimulated by intraislet glucagon.

Very recently, Capozzi et al. published a study that also explored the importance of $\alpha$ to $\beta$ cell communication (31). Interestingly, the authors showed that Ex-9 reduced glucagon-stimulated insulin secretion by approximately $65 \%$ in WT islets and by approximately $80 \%$ in islets prepared from mice selectively lacking the glucagon receptor in $\beta$ cells. This observation is in good agreement with our in vitro data, indicating that the GLP-1 receptor is the main mediator of glucagon-induced insulin release. Capozzi et al. (31) also demonstrated that amino acid-induced (arginine and glutamine) insulin secretion was nearly abolished after simultaneous blockade of glucagon and GLP-1 receptors. We obtained similar findings when we treated perifused WT islets with either Ex-9 alone or with a mixture of Ex-9 and a glucagon receptor antagonist (Figure 6, B and F), strongly suggesting that $\beta$ cell GLP-1 receptors are the major mediator of amino acid-induced insulin secretion and that $\beta$ cell glucagon receptors also contribute to this response (Figure 7).

While we used a chemogenetic approach to suppress glucagon release from $\alpha$ cells, Capozzi et al. (31) carried out studies with islets prepared from mice deficient in the proglucagon gene $(G c g)$. These mutant animals are unable to produce any of the $G c g$ gene products, including glucagon and GLP-1. Consistent with our data involving the chemogenetic silencing of $\alpha$ cells, islets from $G c g$ mutant mice displayed dramatically reduced insulin secretion after treatment with amino acids or a high concentration of glucose (GSIS). Taken together, both studies strongly suggest that glucagon (or glucagon plus GLP-1) release is required for efficient nutrient-induced insulin secretion from WT islets.

Under our experimental conditions, maximum glucagon levels in the perifusion fluid reached 40-80 pM. The intraislet concentration of glucagon is probably considerably higher than this value. Previous work has shown that glucagon can activate GLP-1 receptors expressed in cultured cells at concentrations lower than $1 \mathrm{nM}(5,32)$. These findings strongly suggest that intraislet glucagon levels are sufficiently high to activate $\beta$ cell GLP-1 receptors in mouse islets.

Activation of glucagon and GLP-1 receptors leads to the activation of the stimulatory G protein, $\mathrm{G}_{\mathrm{s}}$, which in turn activates adenyl cyclase, resulting in increased intracellular cAMP levels (15). Interestingly, Capozzi et al. (31) found that cAMP levels were significantly reduced in $\beta$ cells after simultaneous blockade 

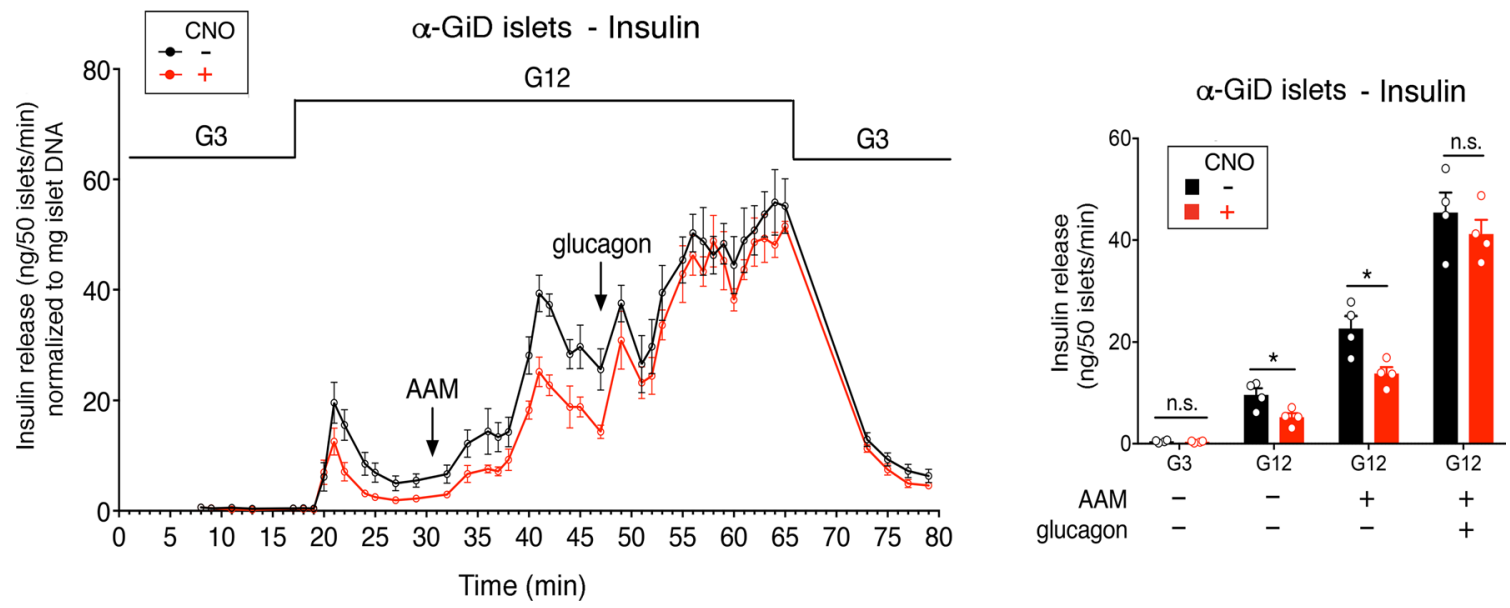

Figure 5. Glucagon restores normal insulin release in CNO-treated $\alpha$-CiD islets. Islets from $\alpha$-GiD mice were perifused with the indicated glucose concentrations ( $3 \mathrm{mM}$ and $12 \mathrm{mM}$; $\mathrm{G} 3$ and $\mathrm{C} 12$, respectively) in the presence (red curve) or absence (black curve) of CNO (10 $\mu \mathrm{M})$ ). At 45 minutes (15 minutes after the addition of AAM), glucagon ( $10 \mathrm{nM}$ ) was added to the perifusion fluid. In the bar graphs, insulin secretion during specific time intervals was expressed as the average of all values measured during a particular perifusion period: G3, 0-15 minutes; $\mathrm{C} 12,15-30$ minutes; G12+AAM, 30-45 minutes; G12+AAM+glucagon, 45-65 minutes. Insulin secretion was normalized to islet DNA content. All islets were prepared from male littermates that were $20-24$ weeks old. Data are given as mean \pm SEM (4 perifusions with 50 islets per perifusion chamber; islets from 2 mice were pooled per perifusion experiment). ${ }^{*} P<$ 0.05 (2-tailed Student's $t$ test). AAM, amino acid mixture (see Methods for details).

of glucagon and GLP-1 receptors, suggesting that glucagon/GLP-1 action on $\beta$ cells maintains cAMP levels within a range required for efficient insulin release.

As discussed above, our data, together with 2 related recent studies $(5,31)$, strongly support the concept that glucagon released from $\alpha$ cells acts in a paracrine fashion primarily on $\beta$ cell GLP-1 receptors to promote GSIS. However, we cannot completely rule out the possibility that the GiD-mediated suppression of $\alpha$ cell activity affects $\beta$ cell function by additional, as yet unknown, paracrine factors or mechanisms. For example, Rodriguez-Diaz et al. (33) demonstrated that human $\alpha$ cells contain acetylcholine that is released when glucose levels are low. However, in contrast to human $\alpha$ cells, acetylcholine release is undetectable in mouse $\alpha$ cells (33), suggesting that changes in acetylcholine secretion from $\alpha$ cells do not contribute to the reductions in GSIS observed after GiD-mediated silencing of $\alpha$ cells in mice.

To further support the conclusion that the insulin secretion deficit observed with CNO-treated $\alpha$-GiD islets was indeed caused by reduced intraislet glucagon signaling, we carried out the rescue experiment shown in Figure 5. We demonstrated that the addition of glucagon (10 nM) to CNO-treated $\alpha$-GiD islets fully restored normal insulin secretion, providing additional evidence that the impairment in insulin secretion displayed by the CNO-treated $\alpha$-GiD islets was caused by the relative lack of intraislet glucagon.

We found that the CNO-mediated decrease in glucagon secretion observed with $\alpha$-GiD islets was relatively small at both G3 and G12 in the absence of amino acids, a major stimulus for glucagon secretion (Figure 4C). In contrast, $\mathrm{CNO}$ treatment of fed or fasted $\alpha$-GiD mice led to a dramatic reduction in plasma glucagon levels in vivo, accompanied by a pronounced decrease in plasma insulin levels (Figure 2). In the in vivo experiments, pancreatic islets are always exposed to a physiological mixture of glucagon-releasing amino acids, providing a possible explanation for the differences in glucagon and insulin release observed with CNO-treated $\alpha$-GiD islets (in the absence of amino acids) versus CNO-treated $\alpha$-GiD mice.

In a previous study, Pedersen et al. (34) injected genetically engineered mice with DT to selectively ablate pancreatic $\alpha$ cells. In contrast to our findings with CNO-treated $\alpha$-GiD mice, the DT-treated mutant mice showed normal i.p. glucose tolerance. One possible explanation for these discrepant findings is that CNO treatment of $\alpha-G i D$ mice led to a dramatic reduction in glucagon release within minutes, while the DT-mediated ablation of $\alpha$ cells occurred over a considerably longer time period, allowing for the potential emergence of compensatory processes. Moreover, we found that the GiD designer receptor was expressed in virtually all $\alpha$ cells. In contrast, Pedersen et al. observed a marked but not complete reduction in the number of $\alpha$ cells (34). 
A
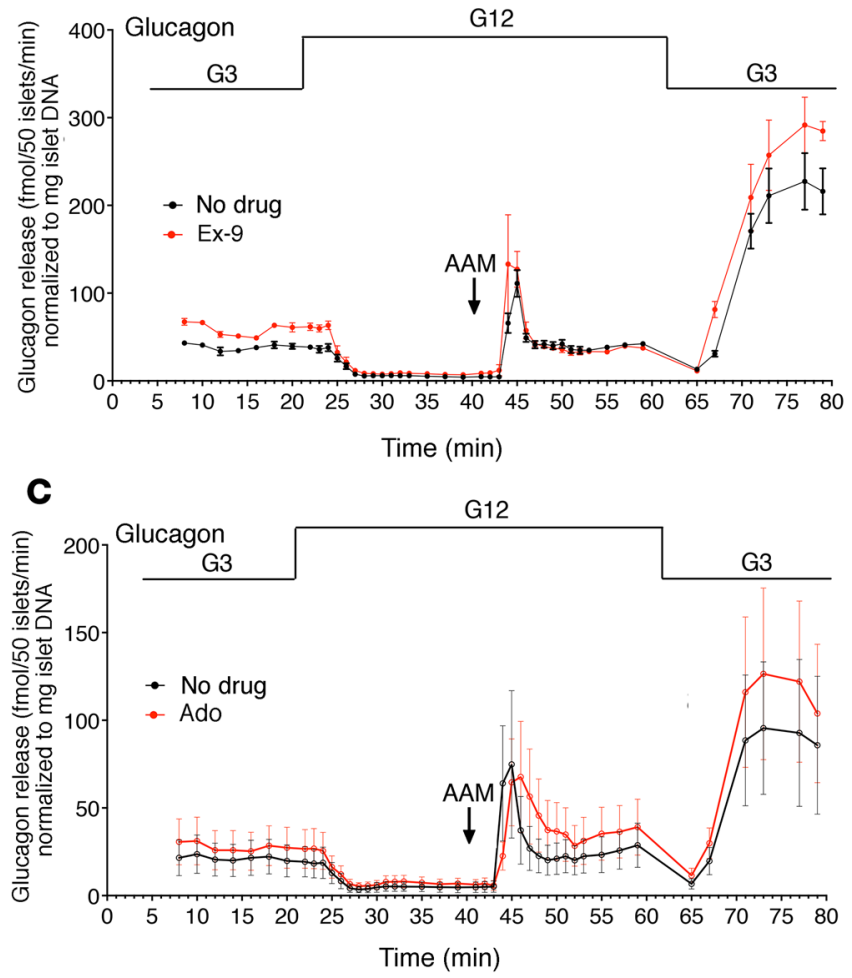

E

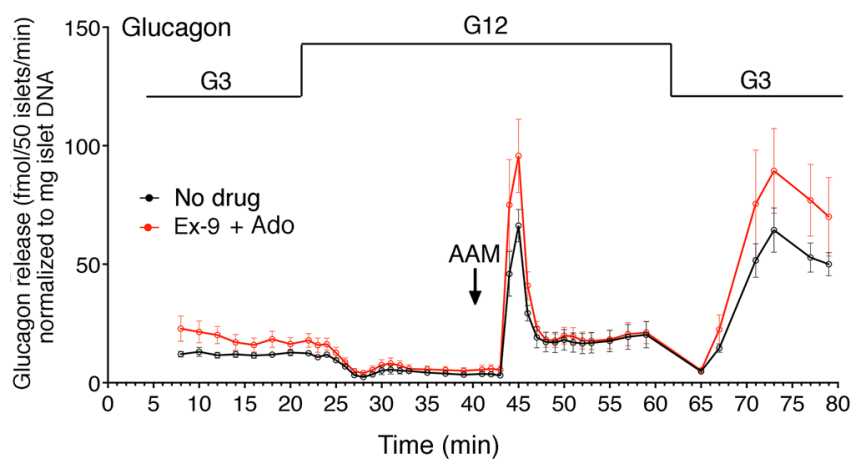

B

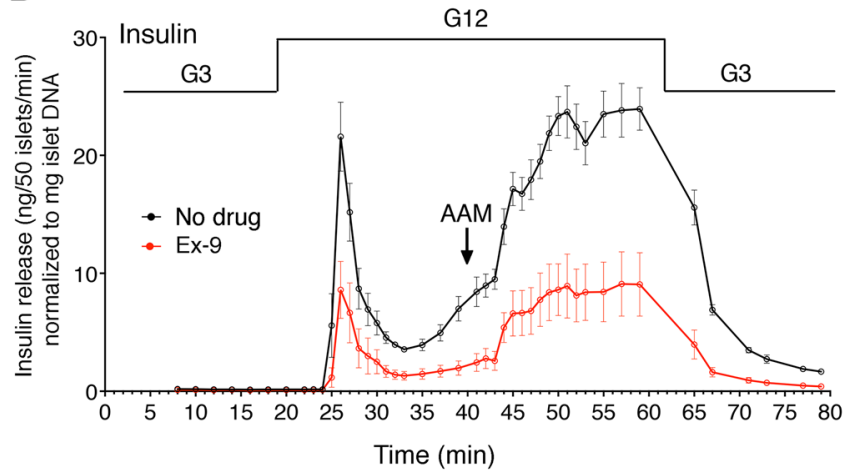

D

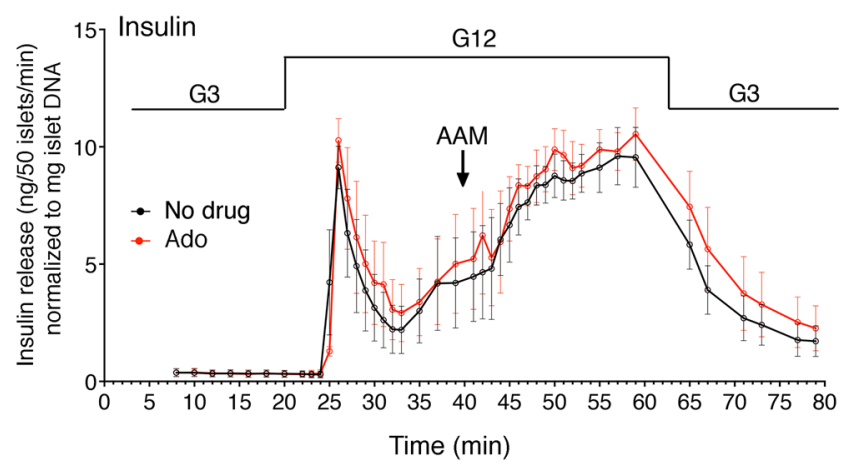

$\mathbf{F}$
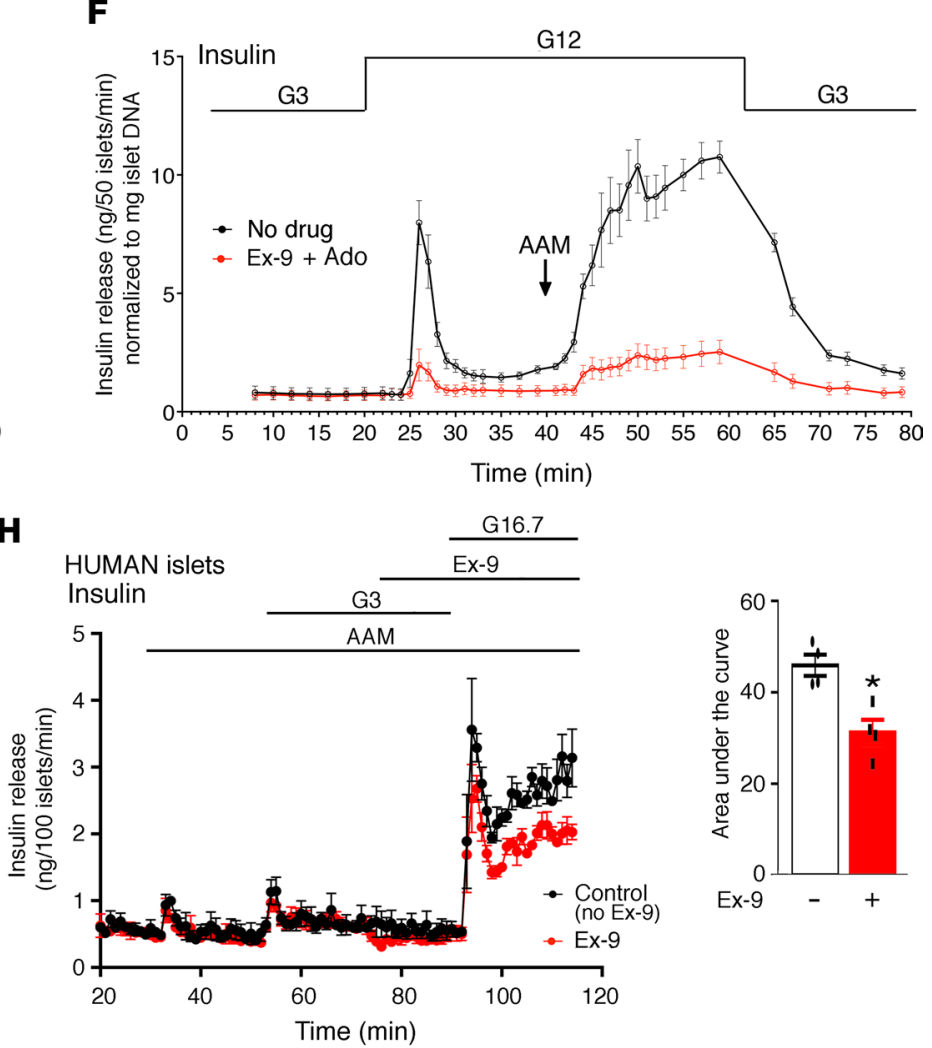
Figure 6. Glucagon release strongly promotes insulin secretion from WT mouse and human islets via activation of GLP-1 receptors. WT mouse pancreatic islets were perifused with 3 and $12 \mathrm{mM}$ of glucose (C3 and G12, respectively) and a physiological amino acid mixture (AAM). Glucagon and insulin secretion were monitored continuously throughout experiments and normalized to islet DNA content. (A and $\mathbf{B})$ Glucagon (A) and insulin (B) secretion in the presence or absence of Ex-9 $(1 \mu \mathrm{M})$, a selective GLP-1 receptor antagonist. (C and D) Glucagon (C) and insulin (D) secretion in the presence or absence of adomeglivant (Ado; $1 \mu \mathrm{M}$ ), a selective glucagon receptor antagonist. (E and $\mathbf{F})$ Glucagon $(\mathbf{E})$ and insulin $(\mathbf{F})$ secretion in the presence or absence of a mixture of Ex-9 $(1 \mu \mathrm{M})$ and Ado $(1 \mu \mathrm{M})$. (G and $\mathbf{H})$ Studies with isolated human islets. Human islets were perifused with 3 and $16.7 \mathrm{mM}$ of glucose (G3 and G16.7, respectively), in the presence of AAM. Glucagon (G) and insulin (H) secretion were monitored continuously throughout experiments. Ex-9 $(1 \mu \mathrm{M})$ was added 20 minutes before stimulation of islets with G16.7. In the control groups, Ex-9 was omitted from perfusate. The bar graph in $\mathbf{H}$ shows insulin release during the G16.7 perifusion period. Data represent mean \pm SEM from 3 or 4 perfusions. ${ }^{*} P<0.05$ ( 2 -tailed Student's $t$ test). Mouse islets were prepared from male mice (age 12-20 weeks). Data are mean \pm SEM ( 3 or 4 perifusions with 50 mouse islets per perifusion chamber; islets from 2 mice were pooled per perifusion experiment).

CNO $(10 \mu \mathrm{M})$ has been shown to interreact with several endogenous biogenic amine GPCRs, including the $5-\mathrm{HT}_{2 \mathrm{~A}}$ receptor subtype (35). Interestingly, a recent study suggests that altered $5-\mathrm{HT}_{2 \mathrm{~A}}$ receptor expression may contribute to defective insulin and glucagon secretion in T2D (36). Since we perifused mouse islets with $10 \mu \mathrm{M} \mathrm{CNO}$, it is possible that CNO also bound to endogenous islet GPCRs, including the $5-\mathrm{HT}_{2 \mathrm{~A}}$ receptor. However, Figure 4, A and B, convincingly shows that insulin and glucagon release were similar in CNO-treated control islets versus untreated control islets. This observation strongly suggests that the potential interaction of CNO with GPCRs endogenously expressed by mouse islets had no significant effect on insulin and glucagon secretion under our experimental conditions.

In the in vivo studies, we injected mice with a standard dose of CNO (1 mg/ $\mathrm{kg}$ i.p.). In a previous study, we monitored CNO plasma levels after i.p. injection of mice with the same CNO dose (37). Plasma CNO levels peaked 15 minutes after CNO injection and then gradually declined throughout the 2-hour observation period. We found no significant back-transformation of CNO to clozapine. Despite the short plasma half-life of CNO in mice, the biological effects that have been observed after acute treatment of DREADD-expressing experimental animals usually last for several hours $(37,38)$. One possibility is that CNO tends to accumulate in tissues, including pancreatic islets (37).

In conclusion, the $\alpha$-GiD mutant mouse line represents what we believe to be an excellent novel tool to explore the physiological and pathophysiological roles of $\alpha$ cell glucagon. In the present study, we provide strong evidence that intraislet glucagon signaling is critical for proper GSIS and glucose homeostasis in vivo. Our in vitro data indicate that this glucagon activity is primarily due to glucagon-dependent stimulation of $\beta$ cell GLP-1 receptors, both in mouse and human islets. The present study greatly advances our knowledge about the in vivo relevance of intraislet glucagon signaling. These findings could pave the way for the development of novel classes of antidiabetic drugs that can modulate intraislet cross-talk between $\alpha$ and $\beta$ cells.

\section{Methods}

Drugs. All drugs, antibodies, and mouse models used are listed in Supplemental Table 1.

Mouse maintenance. Mice were fed ad libitum, kept on a 12-hours light/dark cycle, and maintained at room temperature $\left(23^{\circ} \mathrm{C}\right)$. Mice consumed standard chow $(7022 \mathrm{NIH}-07$ diet, $15 \% \mathrm{kcal}$ fat, energy density $3.1 \mathrm{kcal} / \mathrm{g}$, Envigo Inc.).

Generation of $\alpha$-GiD mice. Mice that carried the Rosa-CAG-LSL-HA-DREADD-P2A-mCitrine allele (Rosa26$L S L-h M 4 D i$ mice) (10) were crossed with Gcg-CreER ${ }^{T 2}$ mice (11). In Rosa26-LSL-hM4Di mice, the GiD receptor, a CNO-sensitive $\mathrm{G}_{\mathrm{i}} \mathrm{DREADD}(9)$, is under the transcriptional control of the strong ubiquitous CAG promoter, separated from the DREADD-coding sequence by a floxed stop cassette. GiD expression can be switched on by Cre-mediated excision of the floxed STOP cassette (note that GiD carries an N-terminal, extracellular HA-epitope tag). The Gcg-CreER ${ }^{T 2}$ mouse line expresses Cre recombinase specifically in $\alpha$ cells without disrupting preproglucagon gene expression. Gcg-CreER ${ }^{T 2}$ mice were initially generated on a mixed genetic background (11). We backcrossed the Gcg-CreER ${ }^{T 2}$ mice for 10 generations onto a C57BL/6 background. In order to induce nuclear Cre activity, we injected the Gcg-CreER ${ }^{T 2}$; Rosa26-LSL-hM4Di mice for 6 consecutive days with TMX (MilliporeSigma) suspended in corn oil (MilliporeSigma) (2 mg TMX i.p. per mouse per day). As outlined in detail in the Results, TMX treatment of Gcg-CreER ${ }^{T 2}$; Rosa26-LSL-hM4Di mice led to the selective expression of GiD in pancreatic $\alpha$ cells. For this reason, we simply refer to these mice as $\alpha$-GiD mice. For control purposes, we injected Rosa26-LSL-hM4Di mice that lacked the Cre transgene with TMX in an identical fashion. These mice did not express the GiD receptor and served as control animals throughout the study. All animals used were maintained on a C57BL/6 background. 
A
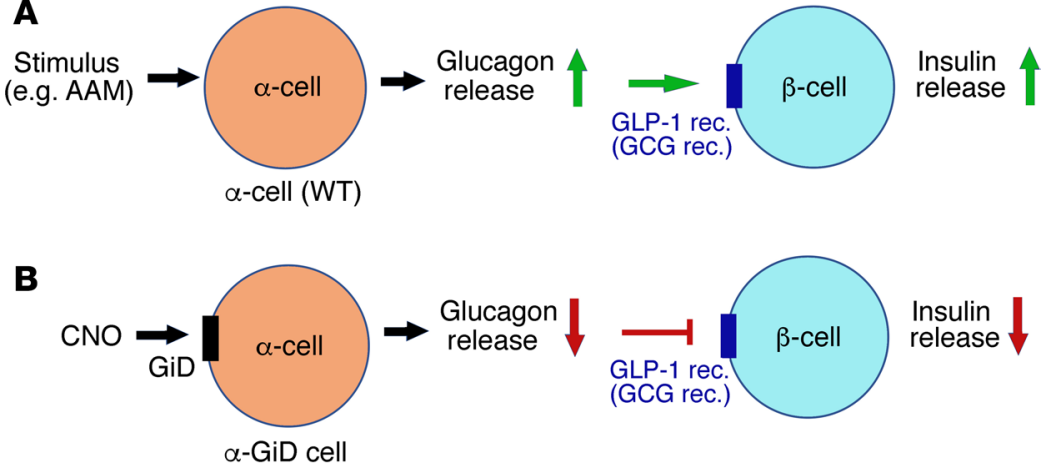

Figure 7. Schematic depicting how glucagon release from $\alpha$ cells stimulates insulin secretion from $\beta$ cells. (A) In WT mouse islets, stimulation of $\alpha$ cells (e.g., by an amino acid mixture [AAM]) promotes the release of insulin from adjacent $\beta$ cells, primarily by activating $\beta$ cell GLP-1 receptors. Glucagon stimulation of $\beta$ cell glucagon receptors (GCG receptors) is predicted to make a minor contribution to this response. (B) In islets from $\alpha$-GiD mice, CNO-mediated activation of the GiD designer receptor inhibits $\alpha$ cell activity, leading to decreased glucagon release, which in turn causes reduced insulin secretion from $\beta$ cells.

Mouse genotyping. Gcg-CreER ${ }^{T 2}$ and Rosa26-LSL-hM4Di mice were genotyped by using mouse tail DNA. To detect the Gcg-CreER ${ }^{T 2}$ transgene, the following PCR primer pair was used: Cre-F, 5'-CCTGGAAAATGCTTCTGTCCG; Cre-R, 5'-CAGGGTGTTATAAGCAATCCC) (size of PCR product: $400 \mathrm{bp}$ ). The presence of the Rosa26-LSL-hM4Di allele was confirmed by the use of the following 2 PCR primers: Di-F, 5'-CGAAGTTATTAGGTCCCTCGAC; Di-R, 5'-TCATAGCGATTGTGGGATGA (size of PCR product: $200 \mathrm{bp}$ ). PCR reactions were carried out using standard procedures.

CNO challenge test, glucose tolerance test, and insulin tolerance test. In vivo metabolic tests were performed with adult male or female mice (age range, 12-30 weeks) using standard procedures. In brief, to assess the in vivo effects of activating the GiD receptor in $\alpha$ cells, $\alpha$-GiD mice and their control littermates were injected with CNO (1 mg/kg i.p. in saline). CNO was administered to both freely fed mice and mice that had been fasted overnight for 12 hours. Blood glucose concentrations were determined using blood collected from the tail vein at defined time points. To study glucose tolerance, mice were fasted overnight for approximately 12 hours and then injected with glucose ( $2 \mathrm{~g} / \mathrm{kg}$ i.p.), either in the presence or absence of $\mathrm{CNO}(1 \mathrm{mg} / \mathrm{kg}$ i.p.). Blood glucose concentrations were determined in the same fashion as in the CNO challenge test. For insulin tolerance testing, mice were fasted for approximately 4 hours and then injected with human insulin (0.75 U/kg i.p.), either in the presence or absence of CNO (1 mg/kg i.p.), followed by the monitoring of blood glucose levels. Blood glucose levels were determined using an automated blood glucose reader (Glucometer Elite Sensor; Bayer).

Measurement of plasma glucagon, insulin, GLP-1, GIP, and SST levels. To measure the plasma levels of several key hormones during the various in vivo metabolic tests, blood samples (40-50 $\mu$ l) collected from the tail vein at different time points $(0,5,15$, and 30 minutes) were transferred to EDTA-coated tubes (SAFET-FILL, RAM Scientific) and centrifuged for plasma collection $\left(10,000 \mathrm{~g}, 10\right.$ minutes, $\left.4^{\circ} \mathrm{C}\right)$. All hormone assays were carried out in the presence of aprotinin (proteinase inhibitor) and DPP-4 inhibitor (KR-62436 hydrate; MilliporeSigma). Insulin, glucagon, GLP-1, GIP, and SST plasma levels were determined by using commercially available ELISA kits (see the Supplemental Table 1 for details).

Perifusion studies with isolated mouse islets. Mouse pancreatic islets were isolated as described previously (39). An automated perifusion system was utilized to dynamically measure glucagon and insulin secretion from pancreatic islets (Biorep Perifusion System). A peristaltic pump pushed HEPES-buffered solution (composition in mM: $125 \mathrm{NaCl}, 5.9 \mathrm{KCl}, 2.56 \mathrm{CaCl}_{2}, 1.2 \mathrm{MgCl}_{2}, 25 \mathrm{HEPES}$, and $0.1 \% \mathrm{BSA}$ [pH 7.4]; perifusion rate: 100 $\mu \mathrm{l} / \mathrm{min}$ ) through a sample container with the islets immobilized in Bio-Gel P-4 Gel (Bio-Rad). Each perifusion chamber contained 50 islets. The concentrations of the various agents used to induce insulin or glucagon secretion are given in the text and/or the figure legends. In perifusion studies, islets were exposed to a physiological AAM of the following composition (final concentrations in $\mathrm{mM}$ ): 0.88 alanine, 0.38 arginine, 0.076 aspartate, 0.19 citrulline, 0.24 glutamate, 0.60 glycine, 0.15 histidine, 0.19 isoleucine, 0.32 leucine, 0.74 lysine, 0.10 methionine, 1.40 ornithine, 0.16 phenylalanine, 0.70 proline, 1.14 serine, 0.54 threonine, 0.15 tryptophan, 0.40 valine, and 2 glutamine. The AAM and other agents were applied with the HEPES-buffered solution. 
Perfusates were collected every minute in 96-well plates for further analysis. The chambers containing the islets were kept at $37^{\circ} \mathrm{C}$, and the perfusates in the collecting plates were kept at $<4^{\circ} \mathrm{C}$. Samples were kept at $-80^{\circ} \mathrm{C}$ until further analysis. Glucagon and insulin concentrations in the perfusates were determined with a mouse glucagon ELISA kit (Mercodia) and an ultrasensitive mouse insulin ELISA kit (Crystal Chem), respectively.

Human islets - source and culture. Human islets were received from the accredited Human Islet Resource Center at the University of Pennsylvania and from the Integrated Islet Distribution Program (https://iidp.coh. org). Islets were obtained from 5 individuals ( 3 males and 2 females) who were normoglycemic at the time of organ isolation. $\mathrm{HbA} 1 \mathrm{c}$ values were $5.2 \%, 5.2 \%, 4.7 \%, 6.0 \%$, and $5.7 \%$, respectively. Donors were $13,35,39$, 60 , and 66 years old, with BMIs of 18.7, 26.9, 34.7, 30.6 and $22.5 \mathrm{~kg} / \mathrm{m}^{2}$, respectively. The cold ischemia time ranged from 8 to 13 hours. Human islets were then transferred and cultured in the laboratory $(14,40)$.

Perifusion studies with human islets. Handpicked human islets (500 islets) were placed on a nylon filter in a plastic perifusion chamber (MilliporeSigma) and were perfused with a flow rate of $1 \mathrm{ml} / \mathrm{min}$ (41). The perifusion apparatus consisted of a computer-controlled low-pressure chromatography system (Bio-Rad Econo System) that allowed programmable rates of flow and glucose concentrations in the perfusate, a water bath $\left(37^{\circ} \mathrm{C}\right)$, and a fraction collector (Bio-Rad; model 2128). The perifusion solution consisted of Krebs buffer ( $\mathrm{pH}$ 7.4) of the following composition (in mM): $114 \mathrm{NaCl}, 5 \mathrm{KCl}, 24 \mathrm{NaHCO}_{3}, 1 \mathrm{MgCl}_{2}, 2.2$ $\mathrm{Ca}^{2+}, 1 \mathrm{P}_{\mathrm{i}}, 10 \mathrm{HEPES}$ ( $\mathrm{pH} 7.4$ ), and $0.25 \%$ BSA equilibrated with $95 \% \mathrm{O}_{2}$ and $5 \% \mathrm{CO}_{2}$. After a 30-minute washout period, a physiological AAM (a mixture of 19 amino acids; $4 \mathrm{mM}$ total) was added to stimulate glucagon secretion (14), followed by the consecutive addition of 3 and $16.7 \mathrm{mM}$ glucose for 40 and 25 minutes, respectively (AAM was present in the perifusion solution throughout the entire experiment). In the experimental group, Ex-9 $(1 \mu \mathrm{M})$ or a mixture of Ex-9 and Ado $(1 \mu \mathrm{M}$ each) were added prior to the addition of $16.7 \mathrm{mM}$ glucose. In the control groups, these drugs were omitted from the perfusate.

Western blotting studies. Immunoblotting studies were carried out by using standard procedures (39). In brief, mouse tissues were lysed in RIPA buffer containing protease and phosphatase inhibitor cocktails (Roche). Protein lysates were subjected to SDS-PAGE without heat denaturation. About $10 \mu \mathrm{g}$ protein was loaded per lane. Immunoreactive proteins were visualized by using SuperSignal West Pico Chemiluminescent Substrate (Pierce) and an Azure C600 gel imaging system (Azure Biosciences). The antibodies that were used are listed in Supplemental Table 1. Primary and secondary antibodies were diluted $1: 1,000$ and $1: 2,000$, respectively.

Immunofluorescence and histological studies. Immunofluorescence microscopic studies were performed using paraffin-embedded mouse islet sections employing standard procedures. Briefly, pancreata were fixed overnight with $4 \%$ paraformaldehyde/PBS and embedded in paraffin. After deparaffinization, tissue sections were subjected to antigen retrieval using IHC-Tek epitope retrieval solution (IHC WORLD) in IHCTek epitope retrieval steamer (IHC WORLD) for 35 minutes. Tissue sections were blocked in PBS-based IHC-Tek Antibody Diluent (IHC WORLD) for insulin and HA coimmunostaining or in 5\% goat serum in PBS for glucagon and HA coimmunostaining for 1 hour and incubated overnight at $4^{\circ} \mathrm{C}$ with a mixture of guinea pig anti-insulin and rabbit anti-HA antibody/mouse anti-glucagon and rabbit anti-HA antibody in blocking medium. After thorough washing of the tissue sections, the insulin, glucagon, and anti-HA primary antibodies were detected by Alexa Fluor 555 goat anti-guinea pig secondary antibody, Alexa Fluor 555 goat anti-mouse secondary antibody, and Alexa Fluor 488 goat anti-rabbit secondary antibody, respectively (for antibody details, see Supplemental Table 1). All sections were counterstained and mounted using ProLong Gold antifade reagent with DAPI (P36931, Thermo Fisher Scientific). Slides were imaged on a Keyence digital microscope (BZ-9000) with a CFI Plan Apo $1 \times 40$ lens.

Statistics. Data are expressed as mean \pm SEM for the indicated number of observations. Prior to performing specific statistical tests, we performed tests for normality and homogeneity of variance. Data were then tested for statistical significance by mixed-effects repeated-measures ANOVA for differences after injection using R software (version 3.5) or by a 2-tailed unpaired Student's $t$ test, as appropriate. A $P$ value of less than 0.05 was considered statistically significant.

Study approval. All animal studies were approved by the National Institute of Diabetes and Digestive and Kidney Diseases Institutional Animal Care and Use Committee. The University of Pennsylvania Institutional Review Board has exempted research in human islets from ethical review because the islets were received from deceased, deidentified organ donors. All pancreata were from deceased donors after having obtained consent from their families through UNOS (United Network for Organ Sharing). 


\section{Author contributions}

LZ and JW designed the study, researched data, and wrote the manuscript. LZ, DD, JP, LW, LFB, and YC carried out experiments and interpreted and analyzed experimental data. BLR, UH, and KHK provided novel mouse models and helpful advice. NMD performed the human islet work, and NMD and FMM analyzed and interpreted the resulting data. KJW carried out the statistical analysis of some of the data. All authors reviewed the manuscript and provided final approval for submission.

\section{Acknowledgments}

This research was funded by the Intramural Research Program of the National Institute of Diabetes and Digestive and Kidney Diseases (NIH). The human islet studies were supported by the Islet Cell Biology Core and Radioimmunoassay and Biomarker Core in the Diabetes and Endocrinology Research Center at the University of Pennsylvania School of Medicine (NIH DK-19525).

Address correspondence to: Jürgen Wess, Molecular Signaling Section, Laboratory of Bioorganic Chemistry, National Institute of Diabetes and Digestive and Kidney Diseases, Bldg. 8A, Room B1A-05, 8 Center Drive, Bethesda, Maryland 20892, USA. Phone: 301.402.3589; Email: jurgenw@niddk.nih.gov.

1. Quesada I, Tudurí E, Ripoll C, Nadal A. Physiology of the pancreatic alpha-cell and glucagon secretion: role in glucose homeostasis and diabetes. J Endocrinol. 2008;199(1):5-19.

2. Ahren B. Glucagon--Early breakthroughs and recent discoveries. Peptides. 2015;67:74-81.

3. Unger RH, Cherrington AD. Glucagonocentric restructuring of diabetes: a pathophysiologic and therapeutic makeover. J Clin Invest. 2012;122(1):4-12.

4. Lee YH, Wang MY, Yu XX, Unger RH. Glucagon is the key factor in the development of diabetes. Diabetologia. 2016;59(7):1372-1375.

5. Svendsen B, et al. Insulin Secretion Depends on Intra-islet Glucagon Signaling. Cell Rep. 2018;25(5):1127-1134.e2.

6. Armbruster BN, Li X, Pausch MH, Herlitze S, Roth BL. Evolving the lock to fit the key to create a family of G protein-coupled receptors potently activated by an inert ligand. Proc Natl Acad Sci USA. 2007;104(12):5163-5168.

7. Urban DJ, Roth BL. DREADDs (designer receptors exclusively activated by designer drugs): chemogenetic tools with therapeutic utility. Annu Rev Pharmacol Toxicol. 2015;55:399-417.

8. Wess J, Nakajima K, Jain S. Novel designer receptors to probe GPCR signaling and physiology. Trends Pharmacol Sci. 2013;34(7):385-392.

9. Rogan SC, Roth BL. Remote control of neuronal signaling. Pharmacol Rev. 2011;63(2):291-315

10. Zhu H, et al. Cre-dependent DREADD (Designer Receptors Exclusively Activated by Designer Drugs) mice. Genesis. 2016;54(8):439-446.

11. Ackermann AM, Zhang J, Heller A, Briker A, Kaestner KH. High-fidelity. Mol Metab. 2017;6(3):236-244.

12. Quoix N, Cheng-Xue R, Guiot Y, Herrera PL, Henquin JC, Gilon P. The GluCre-ROSA26EYFP mouse: a new model for easy identification of living pancreatic alpha-cells. FEBS Lett. 2007;581(22):4235-4240.

13. Cheng-Xue R, et al. Tolbutamide controls glucagon release from mouse islets differently than glucose: involvement of K(ATP) channels from both $\alpha$-cells and $\delta$-cells. Diabetes. 2013;62(5):1612-1622.

14. Deng S, et al. Structural and functional abnormalities in the islets isolated from type 2 diabetic subjects. Diabetes. 2004;53(3):624-632.

15. Ahrén B. Islet G protein-coupled receptors as potential targets for treatment of type 2 diabetes. Nat Rev Drug Discov. 2009;8(5):369-385.

16. Drucker DJ. Mechanisms of Action and Therapeutic Application of Glucagon-like Peptide-1. Cell Metab. 2018;27(4):740-756.

17. Ahrén B. Glucagon-like peptide-1 receptor agonists for type 2 diabetes: A rational drug development. J Diabetes Investig. 2019;10(2):196-201

18. Jorgensen R, Martini L, Schwartz TW, Elling CE. Characterization of glucagon-like peptide-1 receptor beta-arrestin 2 interaction: a high-affinity receptor phenotype. Mol Endocrinol. 2005;19(3):812-823.

19. Galsgaard KD, et al. Disruption of glucagon receptor signaling causes hyperaminoacidemia exposing a possible liver-alpha-cell axis. Am J Physiol Endocrinol Metab. 2018;314(1):E93-E103.

20. Heller RS, Kieffer TJ, Habener JF. Insulinotropic glucagon-like peptide I receptor expression in glucagon-producing alpha-cells of the rat endocrine pancreas. Diabetes. 1997;46(5):785-791.

21. Thorens B, Porret A, Bühler L, Deng SP, Morel P, Widmann C. Cloning and functional expression of the human islet GLP-1 receptor. Demonstration that exendin-4 is an agonist and exendin-(9-39) an antagonist of the receptor. Diabetes. 1993;42(11):1678-1682.

22. Kelly RP, et al. Short-term administration of the glucagon receptor antagonist LY2409021 lowers blood glucose in healthy people and in those with type 2 diabetes. Diabetes Obes Metab. 2015;17(4):414-422.

23. Grover S, Dhanjal JK, Goyal S, Grover A, Sundar D. Computational identification of novel natural inhibitors of glucagon receptor for checking type II diabetes mellitus. BMC Bioinformatics. 2014;15 Suppl 16:S13.

24. Drucker DJ, Asa S. Glucagon gene expression in vertebrate brain. J Biol Chem. 1988;263(27):13475-13478.

25. Lin HV, Accili D. Hormonal regulation of hepatic glucose production in health and disease. Cell Metab. 2011;14(1):9-19.

26. Chu CA, et al. The direct effects of catecholamines on hepatic glucose production occur via alpha(1)- and beta(2)-receptors in 
the dog. Am J Physiol Endocrinol Metab. 2000;279(2):E463-E473.

27. Hayashi Y, et al. Mice deficient for glucagon gene-derived peptides display normoglycemia and hyperplasia of islet \{alpha\}-cells but not of intestinal L-cells. Mol Endocrinol. 2009;23(12):1990-1999.

28. Regard JB, et al. Probing cell type-specific functions of Gi in vivo identifies GPCR regulators of insulin secretion. J Clin Invest. 2007;117(12):4034-4043.

29. Patel YC, Srikant CB. Somatostatin receptors. Trends in endocrinology and metabolism: TEM. 1997;8(10):398-405.

30. Kailey B, et al. SSTR2 is the functionally dominant somatostatin receptor in human pancreatic $\beta$ - and $\alpha$-cells. Am J Physiol Endocrinol Metab. 2012;303(9):E1107-E1116.

31. Capozzi ME, et al. $\beta$ Cell tone is defined by proglucagon peptides through cAMP signaling. JCI Insight. $2019 ; 4(5): 126742$.

32. Graziano MP, Hey PJ, Borkowski D, Chicchi GG, Strader CD. Cloning and functional expression of a human glucagon-like peptide-1 receptor. Biochemical and biophysical research communications. 1993;196(1):141-146.

33. Rodriguez-Diaz R, et al. Alpha cells secrete acetylcholine as a non-neuronal paracrine signal priming beta cell function in humans. Nat Med. 2011;17(7):888-892.

34. Pedersen J, et al. Glucose metabolism is altered after loss of L cells and $\alpha$-cells but not influenced by loss of $\mathrm{K}$ cells. Am J Physiol Endocrinol Metab. 2013;304(1):E60-E73.

35. Jendryka M, et al. Pharmacokinetic and pharmacodynamic actions of clozapine-N-oxide, clozapine, and compound 21 in DREADD-based chemogenetics in mice. Sci Rep. 2019;9(1):4522.

36. Bennet H, et al. Altered serotonin (5-HT) 1D and 2A receptor expression may contribute to defective insulin and glucagon secretion in human type 2 diabetes. Peptides. 2015;71:113-120.

37. Guettier JM, et al. A chemical-genetic approach to study G protein regulation of beta cell function in vivo. Proc Natl Acad Sci USA. 2009;106(45):19197-19202.

38. Alexander GM, et al. Remote control of neuronal activity in transgenic mice expressing evolved G protein-coupled receptors. Neuron. 2009;63(1):27-39.

39. Zhu L, et al. $\beta$-arrestin-2 is an essential regulator of pancreatic $\beta$-cell function under physiological and pathophysiological conditions. Nat Commun. 2017;8:14295.

40. Deng S, et al. Insulin gene transfer enhances the function of human islet grafts. Diabetologia. 2003;46(3):386-393.

41. Doliba NM, et al. Glucokinase activation repairs defective bioenergetics of islets of Langerhans isolated from type 2 diabetics Am J Physiol Endocrinol Metab. 2012;302(1):E87-E102. 